\title{
Obtaining chicken primordial germ cells used for gene transfer: in vitro and in vivo results
}

\author{
Luiza Chojnacka-Puchta • Dorota Sawicka • \\ Pawel Lakota • Grazyna Plucienniczak • \\ Marek Bednarczyk • Andrzej Plucienniczak
}

Received: 17 October 2014 / Revised: 13 January 2015 / Accepted: 13 February 2015 / Published online: 4 March 2015

(C) The Author(s) 2015. This article is published with open access at Springerlink.com

\begin{abstract}
Recently, several attempts have been made to create a generation of transgenic chickens via chimeric intermediates produced by primordial germ cells (PGCs) transfer. This study aimed to compare the influences of different chicken PGCs isolated from circulating blood (bPGCs) or gonads (gPGCs), purification (ACK, Percoll or trypsin) and transfection methods (electroporation or lipofection) on the expression of transgenes in vitro and the migration of modified donor cells to the recipient gonads. The highest average frequency of pEGFP-N1 plasmid-transfected bPGCs $(75.8 \%)$ was achieved with Percoll density gradient centrifugation and electroporation. After ammonium chloride-potassium (ACK) treatment and lipofection, in vitro transgene expression was only detected in $35.2 \%$ of bPGCs. Chimeric chickens were produced from these purified, transfected and cultured cells, and the transgene was detected in the gonads of 44 and $42 \%$ of the recipient embryos that had been injected with bPGCs and gPGCs, respectively. These data confirmed that the combination of PGC purification via Percoll centrifugation and electroporation was an effective method for producing transgenic chickens. Subsequently, we used this method with expression vectors for gene hIFN $\alpha 2 \mathrm{a}$ /hepatitis $\mathrm{B}$ virus surface antigen (HBsAg) under the control of the ovalbumin promoter to generate G0 transgenic chickens. Consequently, we
\end{abstract}

Communicated by: Maciej Szydlowski

$\overline{\text { Luiza Chojnacka-Puchta and Dorota Sawicka contributed equally to this }}$ work.

L. Chojnacka-Puchta $(\bowtie) \cdot$ D. Sawicka $\cdot$ G. Plucienniczak •

A. Plucienniczak

Department of Bioengineering, Institute of Biotechnology and

Antibiotics, Warszawa, Poland

e-mail: chojnackal@iba.waw.pl

P. Lakota $\cdot$ M. Bednarczyk

Department of Animal Biochemistry and Biotechnology, University

of Science and Technology, Bydgoszcz, Poland observed that $4.9 \%$ of the hens and $3.5 \%$ of the roosters carried the hIFN $\alpha 2$ a gene, whereas $16.7 \%$ of the hens and $2.4 \%$ of the roosters carried the HBsAg gene, thus undisputedly confirming the exceptional effectiveness of the applied methods.

Keywords Expression vectors · Primordial germ cells · Chicken embryo $\cdot$ Germline chimeras

\section{Introduction}

Since the successes achieved by the first pioneers in the field of transgenic animal production in the early 1980s (Brinster et al. 1981; Gordon and Ruddle 1981), transgenic techniques have developed rapidly to allow the use of various livestock species as alternate methods for producing biologically active substances. To date, recombinant interferon- $\alpha 2 b, \alpha 1$-trypsin and monoclonal antibodies have been produced in egg white (Mozdziak and Petitte 2004; McGrew et al. 2004). In avian bioengineering, the chicken primordial germ cells (PGCs) have potential applications. PGCs are specialised germ cells that can transfer genetic information and are, thus, ideal for generating transgenic chickens. To produce transgenic animals, from transferred modified PGCs via chimeric intermediates, we must fully understand the complete mechanisms associated with non-viral gene delivery into embryonic cells, as well as the required chicken cell isolation, purification, culture and transfection conditions. It is also important to address the characteristics of the promoter, enhancer, regulatory and tissue-specific elements in transgenic birds.

In chickens, PGCs have been isolated from the blood (bPGCs) or gonads (gPGCs) of embryos at various stages of development through the use of different purification 
techniques, including Ficoll, Nycodenz, Percoll density gradient centrifugation, ammonium chloride-potassium (ACK) lysis buffer (Yamamoto et al. 2007), immunomagnetic cell sorting (MACS) and fluorescence-activated cell sorting (FACS) (Mozdziak et al. 2005). These PGCs can be transfected in vitro with avian retroviruses or via non-viral methods and subsequently injected into recipient embryos (reviewed in Song et al. 2010). This study aimed to compare the influences of different chicken PGCs isolation (from circulating blood or gonads), purification (ACK, Percoll or trypsin) and transfection (electroporation or lipofection) methods on in vitro transgene expression. We demonstrate the high percentage of transfected PGCs that express the EGFP by 24-h culturing in a G418-containing medium and their migration to the gonads of recipient embryos. To distinguish the PGCs from other cells, we used periodic acid-Schiff (PAS) staining and immunocytochemistry. The in vitro and in vivo experiments confirmed that PGCs purification with a combination of Percoll centrifugation and electroporation is a potentially powerful tool for putative germline chimera (G0) production. In addition, modification of the strong ovalbumin promoter with regard to own genetic expression constructs might increase the level of protein production in the next generation and, ultimately, in egg whites.

\section{Materials and methods}

\section{Expression constructs}

The pEGFP-N1 plasmid (Clontech Laboratories, Inc., Mountain View, CA, USA) was used as the control DNA for comparing the isolation and transfection methods. To express human IFN $\alpha 2 \mathrm{a} /$ hepatitis B virus surface antigen ( $\mathrm{HBsAg}$, GenBank accession no. Z35717), the final vectors were constructed on the pEGFP-N1 backbone (pC_) under the control of the chicken ovalbumin promoter (OVA), including the enhancer and regulatory sequences. The original cytomegalovirus (CMV) promoter sequence was deleted from the pEGFPN1 plasmid. The chicken ovalbumin promoter region and DNA fragment that encoded interferon $\alpha 2 \mathrm{a}$ were taken from the pOVA and pOVAINT vectors (IBA, Warsaw, Poland; described previously by Bednarczyk et al. 2003) and inserted into $\mathrm{pC}_{-}$(pC_OVA). The amplified enhancer region $5^{\prime}$ flank of approximately $1,000 \mathrm{bp}$ and the estrogen response element (ERE) sequence were isolated by polyacrylamide gel electrophoresis, digested with BamHI and SalI, and inserted into the pBlueScript SK+ vector. These DNA regions were amplified from $100 \mathrm{ng}$ of total chicken DNA. Specific primers, ERES, EREN, 5OVAB and 5OVAN, are as detailed in Table 1.

The first and second pairs of primers contained the $S a c$ I and NotI and the BamHI and NotI recognition sequences,
Table 1 Primers used in this study

\begin{tabular}{ll}
\hline Primer & Sequence \\
\hline ERES & 5'aactcegcggctgcagaaaatgccaggtgga \\
EREN & 5'gaaagcggccgctctagagagagtaagcaacaatct \\
5OVAB & 5'gaaaggatccatgtcagtctgcagaaagagaaa \\
5OVAN & 5'aactgcggccgcatttctcactcactcacctctccaa \\
GFP1 & 5'gacgacggcaactacaagac \\
GFP2 & 5'gtcacgaactccagcaggac \\
IFN_F1 & 5'cagaggaccatgctgactgatc \\
RevG1 & 5'gccggtggtgcagatgaactt \\
HBsAg_F2 & 5'tcagggcatattgaccacag \\
RevG2 & 5'gccggtggtgcagatgaactt \\
\hline
\end{tabular}

respectively. Polymerase chain reaction (PCR) was performed in a total reaction volume of $50 \mu \mathrm{l}$ that included Buffer 1 and thermostable DNA polymerases from the Expand Long Template PCR System (Roche Diagnostics, Mannheim, Germany). Following an initial 2-min denaturation step at $95{ }^{\circ} \mathrm{C}$, thermostable DNA polymerase was added when the sample achieved a temperature of $90^{\circ} \mathrm{C}$, after which 32 PCR cycles were performed. Each cycle comprised $20 \mathrm{~s}$ at $94{ }^{\circ} \mathrm{C}, 30 \mathrm{~s}$ at $58^{\circ} \mathrm{C}$ and 2 min at $68^{\circ} \mathrm{C}$. The fragments were ligated into the prepared pC_OVA. preS1/preS2/S HBV was obtained by digesting the $\mathrm{pUC}-\mathrm{HBV}$ vector (IBA, Warsaw, Poland). The ligation products were transformed into the NEB beta-10 strain of Escherichia coli (New England Biolabs, Ipswich, MA, USA). The plasmids used for transfection were isolated with the EndoFree Plasmid Maxi Kit (Qiagen, Venlo, the Netherlands).

\section{Isolation of PGCs}

Freshly laid Ross 308 chicken eggs were obtained from a commercial breeding farm (Malec H. Poultry Farm, Góra Kalwaria, Poland) and used as the PGCs donors and recipients. The eggs were incubated at $37.8{ }^{\circ} \mathrm{C}$ and the chicken embryos were subsequently staged according to Hamburger and Hamilton (HH staging) (1951). An outline of the in vitro and in vivo studies is presented Fig. 1.

bPGCs isolation and purification

\section{Percoll density gradient centrifugation}

PGCs were isolated from embryonic blood at the 14-16 HH stage (50-56 h of incubation) and were suspended in OptiMEM (Gibco Invitrogen Co., Grand Island, NY, USA) supplemented with antibiotics $(1 \times$ Penicillin/Streptomycin, Sigma-Aldrich Corporation, St. Louis, MO, USA). One part of the PGCs was purified as described previously (Oishi 2010). Approximately $11.6 \times 10^{6}$ cells were collected, and 
Fig. 1 Outline of the in vitro and in vivo studies in which different methods of purification (bPGCs: Percoll, ACK lysis buffer; gPGCs: trypsin digestion, trypsin and Percoll) and transfection (bPGCs and gPGCs: pEGFP-N1 vector electroporation and lipofection) were compared. The most effective combinations for the two types (sources) of cells (bPGCs and gPGCs) were selected for the in vivo experiments

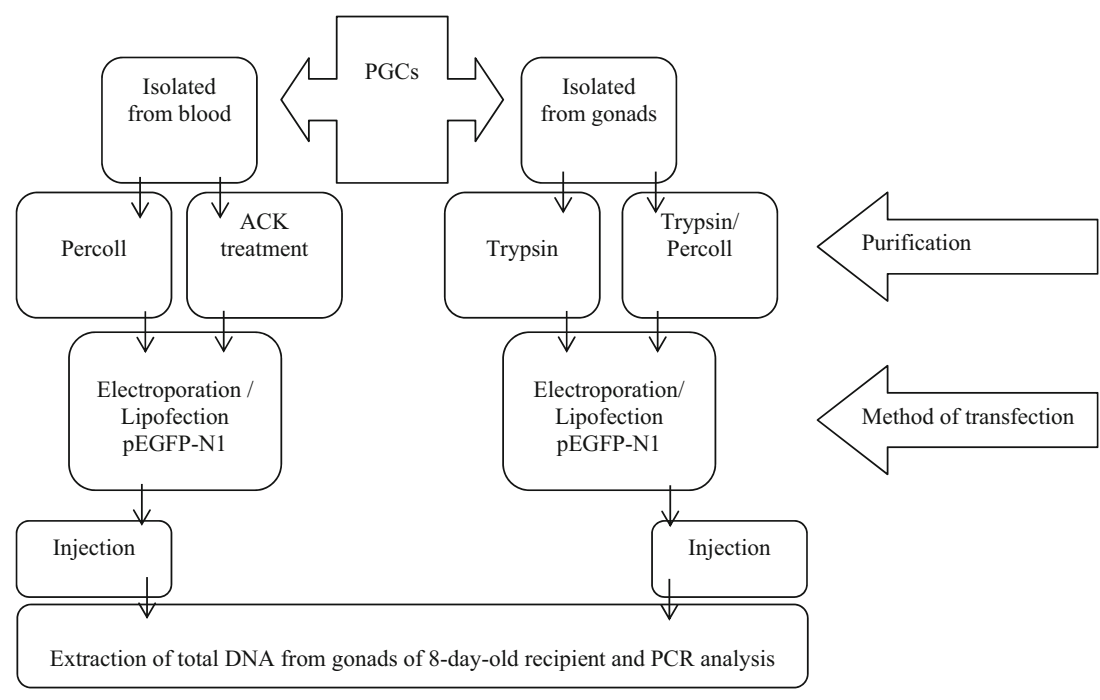

$3 \mathrm{ml}$ of each Percoll density solution (50\%, $25 \% 12.5 \%$ at pH 8.5-9.5; Sigma) were prepared in OptiMEM supplemented with $5 \%$ fetal bovine serum (FBS, Gibco Invitrogen Co., Grand Island, NY, USA). The collected blood containing the PGCs was suspended in OptiMEM with $5 \%$ FBS and layered over the top of the gradient. After centrifugation, the cell layer between the 50 and $25 \%$ Percoll levels was collected and washed twice in OptiMEM with antibiotics.

\section{PGCs purification from red blood cells with ACK lysis buffer}

A portion of the embryonic blood was treated with $1 \mathrm{ml}$ of ACK lysis buffer $\left(0.15 \mathrm{M} \mathrm{NH}_{4} \mathrm{Cl}, 10 \mathrm{mM} \mathrm{KHCO}{ }_{3}, 0.1 \mathrm{mM}\right.$ EDTA). The blood-derived supernatant, which included the PGCs, was centrifuged twice at 2,000 rpm for $7 \mathrm{~min}$ at $20{ }^{\circ} \mathrm{C}$. The PGCs pellet was suspended in OptiMEM with antibiotics.

gPGCs isolation and purification

Gonadal cells were retrieved from the gonads of 6-day-old embryos (28-29 HH). The gonadal tissues were dissociated by pipetting with $0.25 \%$ trypsin (HyClone/Thermo Fisher Scientific, Waltham, MA, USA) at $37{ }^{\circ} \mathrm{C}$ and the reaction was stopped by the addition of $10 \%$ FBS. A second group of gonadal cells, after trypsin treatment, was purified via a Percoll density gradient.

PAS staining, immunocytochemistry and FACS analysis

The cells were fixed in $4 \%$ paraformaldehyde for $5 \mathrm{~min}$ and rinsed twice in $1 \times$ PBS (Gibco). The fixed cells were immersed in periodic acid solution for $5 \mathrm{~min}$. After washing with $1 \times$ PBS, the cells were then immersed in Schiff's solution for $15 \mathrm{~min}$. The PAS-stained bPGCs were observed under an inverted microscope after they were washed twice in $1 \times$
PBS. An anti-SSEA-1 antibody was used to analyse specific surface antigens on the germ cells; briefly, the bPGCs were fixed in $1 \%$ paraformaldehyde-PBS at room temperature for 15 min, after which SSEA-1 expression was determined with an FITC-conjugated antibody $\left(1 \mu \mathrm{g}\right.$ per $1 \times 10^{6}$ cells) (Santa Cruz Biotechnology, Santa Cruz, CA, USA). FACS was performed using FACS Aria (BD Biosciences, San Jose, CA, USA) to collect a suspension of SSEA-1-positive germ cells.

Microscopy and cell counting

The viability of the purified PGCs in all experiments was determined with a haemocytometer according to the $0.4 \%$ $(w / v)$ trypan blue exclusion method (Freshney 1987). The live growing cells, morphological differences and prefixed immunochemically labelled cultures were observed with either bright-field, Nomarski contrast or ultraviolet (UV) light under a fluorescent Eclipse TE2000-E or the Eclipse E800 microscope (Nikon Corporation, Tokyo, Japan). The images were captured with a Nikon or ORCA (Hamamatsu Photonics, Hamamatsu City, Japan) camera coupled to the microscope and processed using the computer-based Nikon EZ-C1 programmable image analyser. A confocal EZ-C1 module and PFS system were used to obtain detailed images of the cells. The emitted fluorescence was collected by filters: FITC (515/30) and PerCp (605/75) after excitation via an argon laser $(488 \mathrm{~nm})$.

PGCs transfection and culture conditions

The cells were purified as follows:

1. bPGCs: ACK treatment or Percoll

2. gPGCs: trypsin or trypsin and Percoll 
After purification, the cells were transfected using two methods: electroporation at $200 \mathrm{~V}$ and $900 \mu \mathrm{F}$ for $32 \mathrm{~ms}$ or lipofection with Xtreme (Roche) and $20 \mu \mathrm{g}$ pEGFP-N1. Next, they were seeded into 4 -well plates with a density of $5 \times 10^{5}$ cells and over a period of $24 \mathrm{~h}$, the PGCs were grown in OptiMEM I supplemented with antibiotics at $37{ }^{\circ} \mathrm{C}$ and $5 \%$ $\mathrm{CO}_{2}$ in air. After $24 \mathrm{~h}$, the medium was replaced with OptiMEM I C [C: supplemented with $2 \%$ chicken serum (Gibco), $10 \%$ FBS (Sigma), $20 \mathrm{ng} / \mathrm{ml} \mathrm{bFGF,} \mathrm{basic} \mathrm{fibroblast}$ growth factor (Sigma), $9 \mathrm{ng} / \mathrm{ml} \mathrm{mLIF}$, murine leukaemia inhibitory factor (Sigma), $5 \mathrm{ng} / \mathrm{ml} \mathrm{hSCF}$, human stem cell factor (Sigma), antibiotics and G418 (50 $\mu \mathrm{g} / \mathrm{ml}$, Sigma)]. Every 3 days, the medium was changed.

Transfer of modified bPGCs and gPGCs to the chick embryos

Transfected bPGCs or gPGCs that had been obtained after purification by Percoll density gradient centrifugation and electroporation of the pEGFP-N1 vector were cultured for 7 days in OptiMEM I C before being transferred into chick embryos at HH stages 14-16. A circular hole was made in the narrow part of the recipient eggshell. Then, $1-1.5 \mu \mathrm{l}$ of a chicken PGC suspension was injected into the dorsal aorta of the recipient embryo. After injection, the eggshells were sealed and the eggs were returned to the incubator for a total of 8 complete days of incubation at $37.8{ }^{\circ} \mathrm{C}$ in $62-65 \%$ relative humidity.

Observation of the EGFP expression via fluorescent microscope and the analysis of EGFP presence through PCR

The gonads from 8-day-old embryos (control and experimental groups) were dissected and observed after excitation via argon laser $(488 \mathrm{~nm})$. Total DNA was extracted from the gonads of the 8-day-old recipient with the DNeasy Blood \& Tissue Kit (Qiagen). PCR was performed using the primers GFP1 and GFP2 (Table 1). The 50- $\mu$ l reaction mixtures contained $10 \mathrm{ng}$ of DNA each, and the reactions were performed as described above. The PCR products were separated on $1 \%$ agarose gel in $1 \times$ Tris-acetate-EDTA (TAE) buffer and visualised by ethidium bromide staining.

\section{The preparation of germline chimeric chicken $(G 0)$}

The preparation of bPGCs transfected with IFN $\alpha 2 \mathrm{a} /$ antigen HBsAg under ovalbumin promoter was as follows. PGCs were isolated from embryonic blood at the 14-16 HH stage and purified via Percoll density gradient centrifugation. Cells transfected via electroporation with $\mathrm{pC}-\mathrm{OVAIFN} / \mathrm{pC}$ OVAHBV (IFN $\alpha 2 \mathrm{a} /$ antigen HBsAg) were seeded into 4well plates with a density of $5 \times 10^{5}$ cells and cultured for 1 week under antibiotic selection in OptiMEM I C.
Microinjection

After 7 days in culture, $1.5 \mu \mathrm{l}$ of bPGCs were injected into the recipient embryos (HH stages 14-16) and incubated for 18 days at $37.8{ }^{\circ} \mathrm{C}$ and $65 \%$ relative humidity and were rocked at $35^{\circ}$ every $2 \mathrm{~h}$ except during the last 4 days. The incubation continued until hatching occurred. Untreated fertilised eggs were used as controls.

\section{DNA extraction and PCR analysis}

Samples of semen DNA were obtained from mature G0 roosters and blastodermal DNA cells (BCs) were obtained from hens after fertilisation with Ross 308 male. The DNA was extracted with a cell lysis solution buffer (10 mM Tris$\mathrm{HCl} \mathrm{pH} \mathrm{7.6,} 10 \mathrm{mM}$ EDTA, $50 \mathrm{mM} \mathrm{NaCl}$ and $0.2 \% \mathrm{SDS}$ ), to which proteinase $\mathrm{K}$ had been added at a final concentration of $0.1 \mathrm{mg} / \mathrm{ml}$ and was incubated for $2 \mathrm{~h}$ at $56{ }^{\circ} \mathrm{C}$. Next, $4 \mathrm{mg} / \mathrm{ml}$ of RNAse were added. The proteins were removed by phenol:chloroform $(1: 1 v / v)$ extraction and the DNA was precipitated with ethanol and resuspended in Tris-EDTA (TE) buffer (10 mM Tris-HCl, pH 8.0, 1 mM EDTA).

PCR analyses for the presence of exogenous genes were performed with SuperHotTaq DNA Polymerase (Bioron $\mathrm{GmbH}$, Ludwigshafen, Germany) on 30-ng DNA samples. The primers were IFN_F, RevG, HBsAg_F and RevG (Table 1). The PCR amplifications were performed for $30 \mathrm{cy}-$ cles. The reaction products were loaded onto an $8 \%$ polyacrylamide gel for molecular sizing. Genomic DNA from an untreated rooster was used as the negative control.

\section{Statistical data analysis}

The statistical analysis was performed with the assistance of the SAS 9.2 software package (2010). To compare the effectiveness of the two purification methods and two cell transfection methods, a two-way analysis of variance for an unbalanced set-up was used (procedure: GLM, III type of quadrant sums). A detailed analysis of the simple effects was performed with Tukey's honest significant difference (HSD) procedure for an individual classification based on a combination of the purification and transfection methods at a significance level of $\alpha=0.05$ and confidence level of $1-\alpha=0.95$. The confidence ranges for the mean results were established at the same level of confidence (procedures: GLM and MEANS). In the quantitative analysis of the interactions between the purification and transfection methods, the significance tests and confidence ranges $(1-\alpha=0.95)$ were applied for the appropriate contrasts. The preliminary results analysis demonstrated that the frequently recommended transformation of fractions (Sokal and Rohlf 1995) was practically meaningless in the case of the analysed data; therefore, it was not used in the presented detailed comparisons. 


\section{Results}

\section{Characterisation of PGCs}

This study was based on technology that incorporated non-viral methods applied to modified PGCs to generate germline chimeras. The migration and movement of PGCs through the bloodstream in chicken embryos enabled us to collect these cells from embryonic blood and inject modified PGCs into recipients. Additionally, gonadal PGCs from 6-day-old embryos could proliferate in culture and migrate to the germinal ridge in the recipient. The assessment of PGCs isolation and purification is illustrated in Fig. 2. PGCs purification enabled the production of a homogeneous suspension of viable PGCs (Fig. 2a, c), compared with those obtained with ACK-treated PGCs (Fig. 2b) suspensions. We could also confirm the identities of the PGCs with PAS staining (Fig. 3a) and immunocytochemical methods (Fig. 3b, d). PGCs purified via Percoll centrifugation and labelled with anti-SSEA-1-FITC were found to have an SSEA-1 expression rate of $64 \%$ as determined by FACS (Fig. 4).
Comparison of the different purification and transfection methods

To study the effects of the purification and transfection methods, the pEGFP-N1 plasmid was used. Cells expressing EGFP are obvious 7 days after transfection (Fig. 5a, b). After 14 days in culture and G418 selection, few fluorescing cells were evident (Fig. 5c, d).

\section{Assessment of bPGCs}

The effectiveness of the use of two purification methods (Percoll or ACK) and two transfection methods (electroporation or lipofection) on the bPGCs was assessed by trypan blue staining after the cells had been cultured to G418 selection $24 \mathrm{~h}$ later. The highest mean percentage of transfected bPGCs was $75.8 \%$, and this level of transfection was acquired by purifying the cells via Percoll centrifugation followed by electroporation [95\% confidence interval (CI): 73.5-78.1\%; Fig. 6]. The combination of lysis in ACK buffer with lipofection yielded the lowest percentage of transfected cells (35.2 \%; $95 \%$ CI: 31.4-39.1\%).
Fig. 2 Morphological observations of PGCs that were isolated from the blood of embryos (stages 14-16 HH) and gonads of embryos (28-29 HH), purified and cultured for $24 \mathrm{~h}$. bPGCs collected from between the 25 and $50 \%$ Percoll dilution layers (a) (20× magnification). bPGCs after ACK buffer treatment (b). gPGCs are shown after trypsin digestion, Percoll purified and cultured for $24 \mathrm{~h} \mathrm{(c)}$ (40× magnification) a

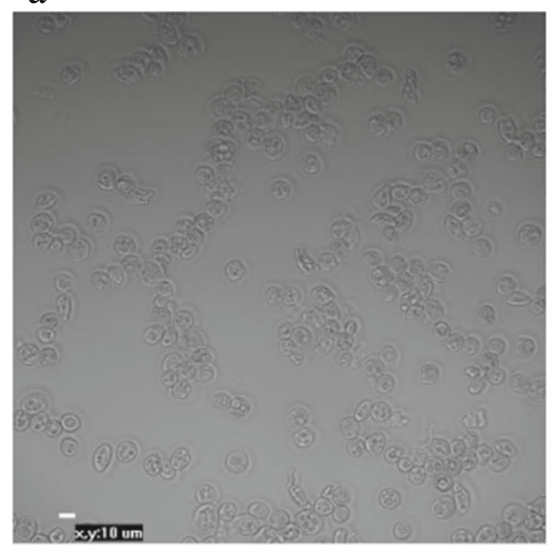

b

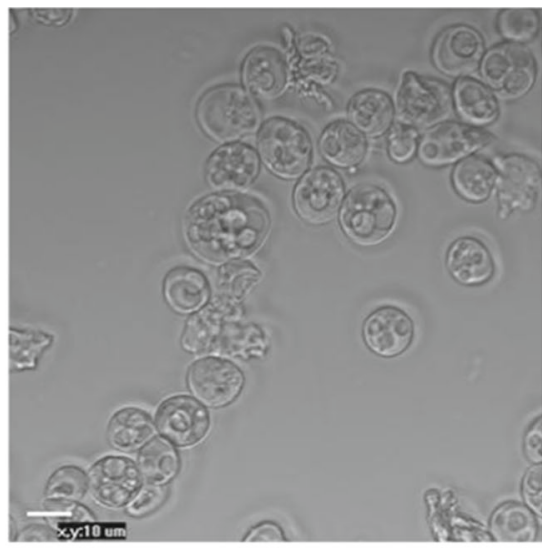

c

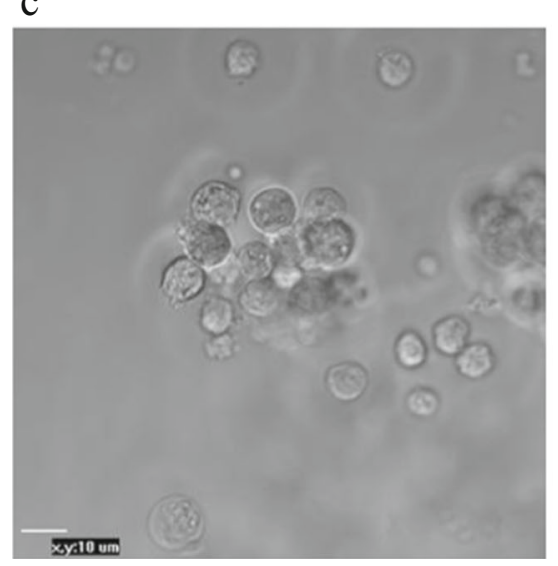


Fig. 3 PAS histochemistry indicating the presence of glycogen vesicles and red-stained chicken PGCs (a) (40× magnification).

Immunofluorescence staining results for the specific cell surface antigen SSEA-1; chicken blood PGCs were found (stages 14-16 $\mathrm{HH}$ ) to express SSEA-1. AntiSSEA-PerCp-positive cells are shown in (b) and brightness (c) and anti-SSEA-1-FITC-positive cells are shown in (d) and brightness (e) $(20 \times$

magnification)

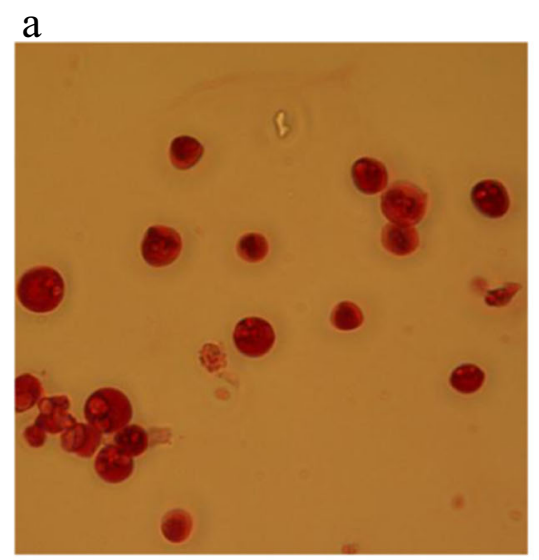

b
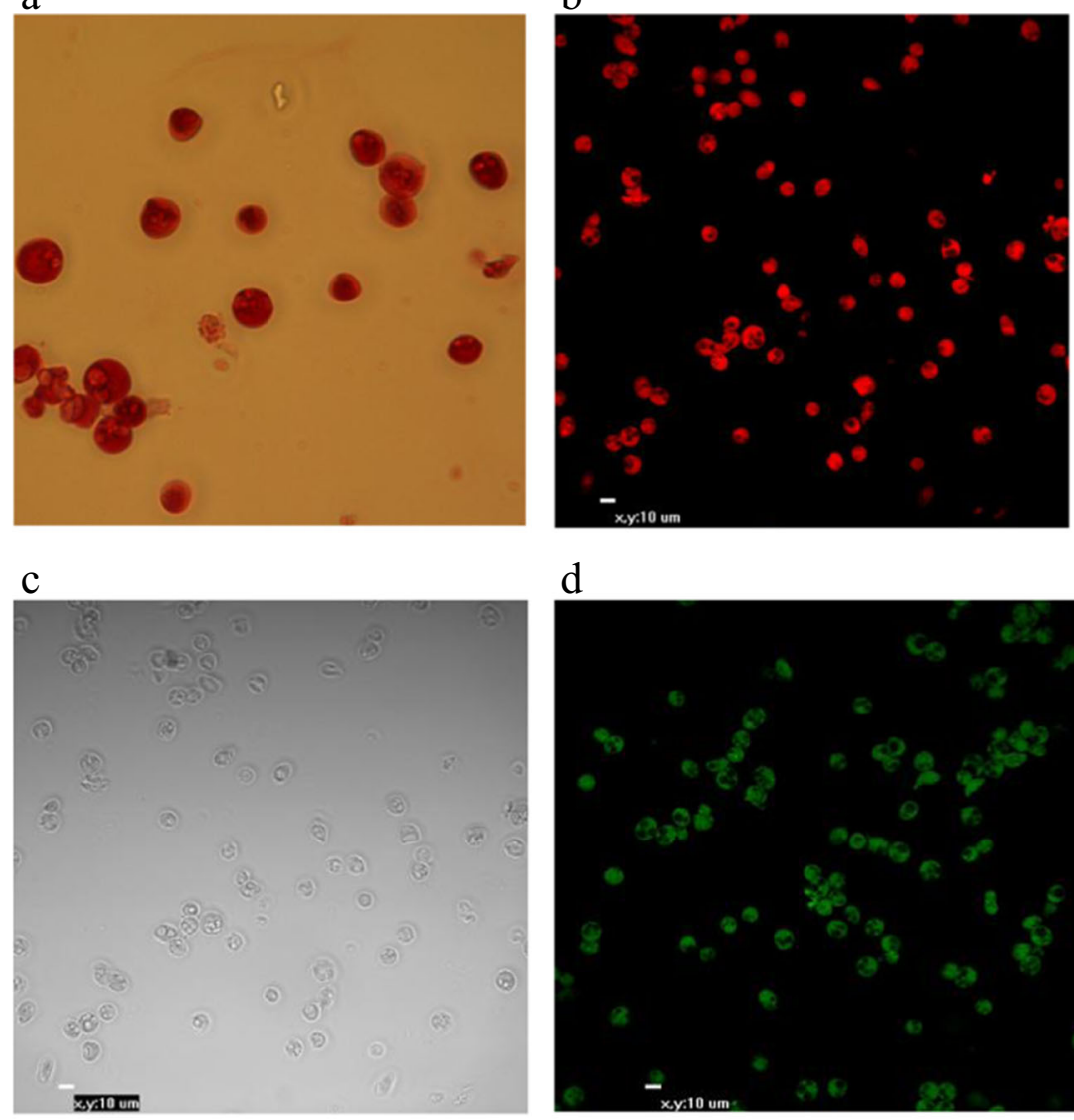

d

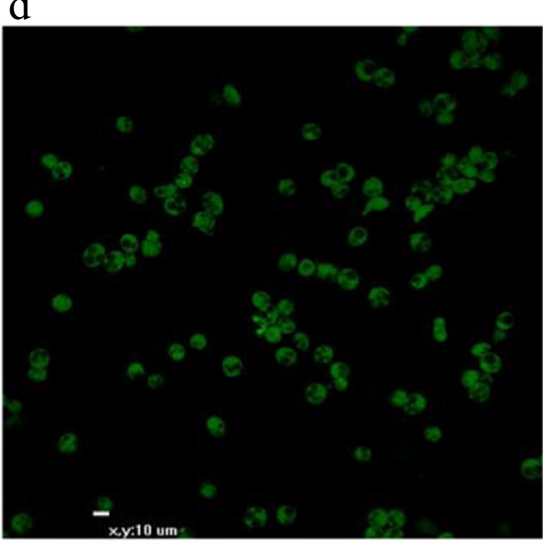

e

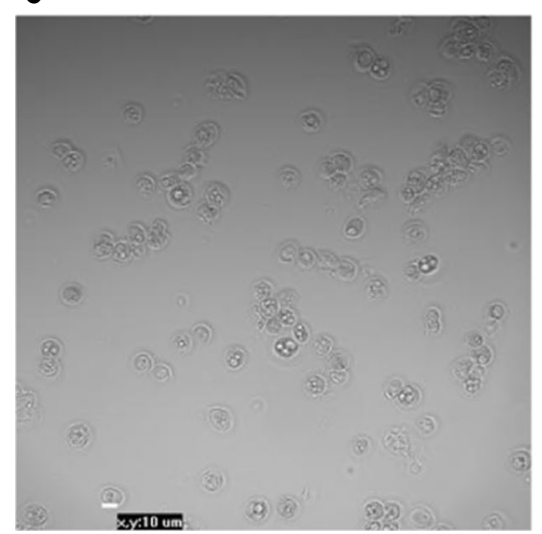

\section{Assessment of gPGCs}

The effectiveness of the use of two purification methods (trypsin digestion with or without Percoll gradient centrifugation) and two transfection methods (electroporation or lipofection) on gPGCs was assessed by trypan blue staining after the cells had been cultured to G418 selection for $24 \mathrm{~h}$ later. The results are shown in Fig. 7. Of the gPGCs, the highest mean percentage of transfected cells was $73.8 \%$ (95\% CI: 70.2-77.4 \%); this was acquired by cell purification with both trypsin digestion and Percoll gradient centrifugation followed by transfection via electroporation. The most unfavourable setup that resulted in the lowest mean percentage of cells (31.8 \%; $95 \%$ CI: 30.6-32.9\%) was purification via trypsin digestion followed by transfection via lipofection.

Results of the transfer of modified bPGCs/gPGCs to chicken embryos

The injected embryos were characterised by their high viability rates $(87-88 \%)$. Table 2 shows the number of groups and the percentages of live and dead recipient (bPGCs/gPGCs) 
Fig. 4 FACS analysis of Percollpurified bPGCs labelled for SSEA-1-FITC expression. Flow cytometry analysis showed an expression rate of $64 \%$

Fig. 5 Results of a culture of bPGCs/gPGCs subjected to G418 selection 7 days later $(\mathbf{a}, \mathbf{b})$ and few positive EGFP bPGCs/ gPGCs remain after 14 days $(\mathbf{c}, \mathbf{d})$ post-transfection with the pEGFP-N1 vector. EGFP proteinexpressing cells were observed on the different surfaces of the specimens (40× magnification)
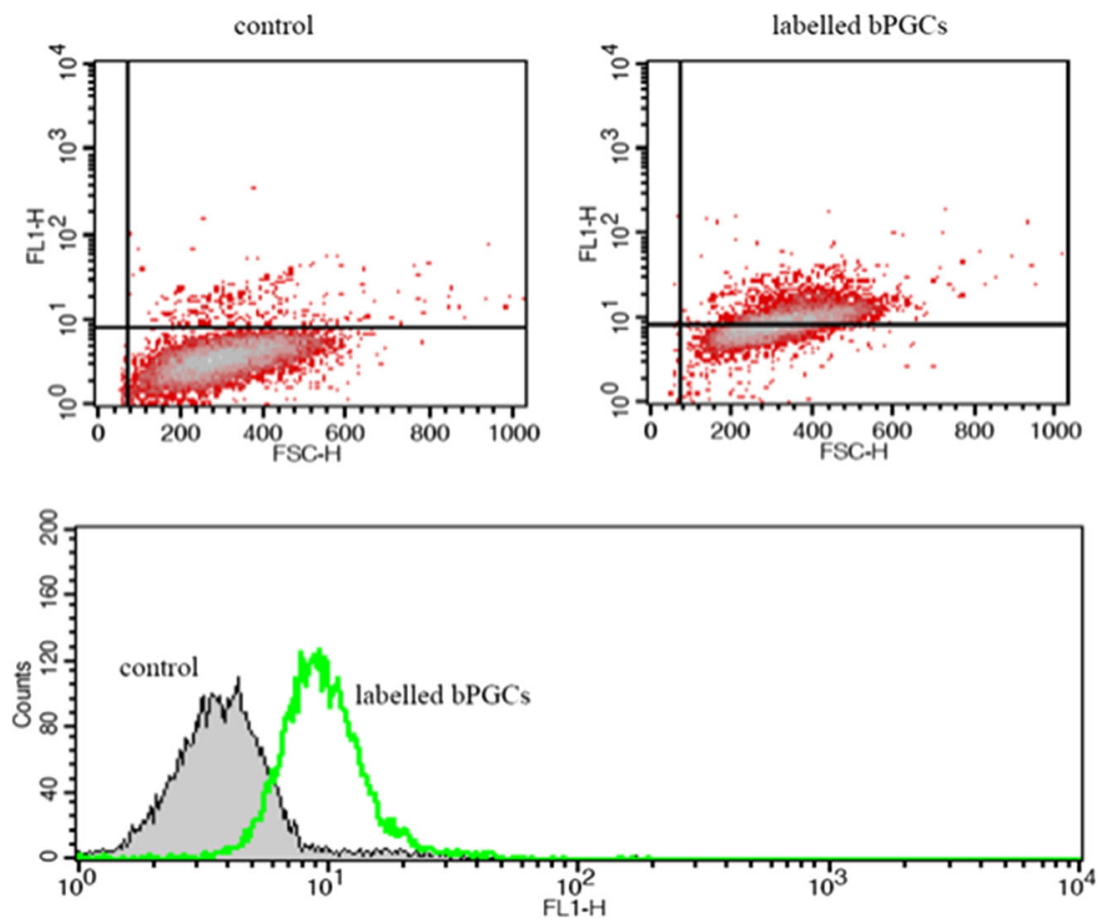

$\mathrm{a}$

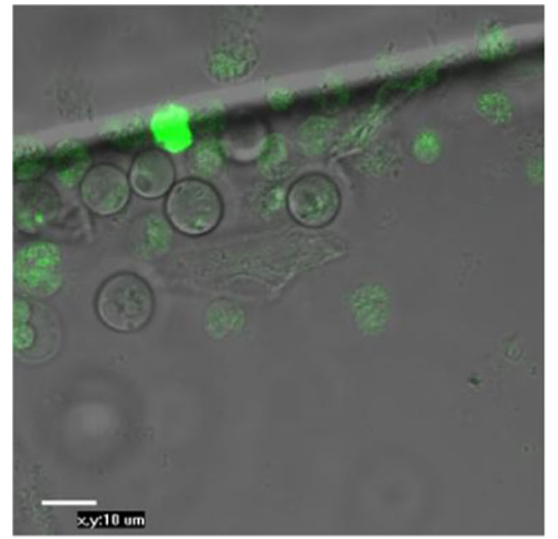

C

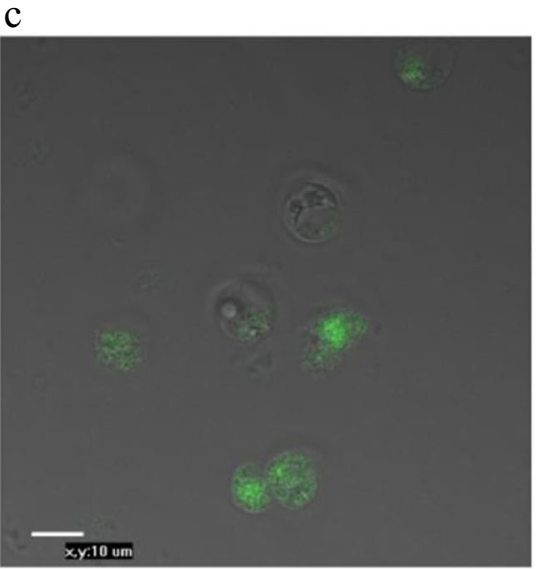

b

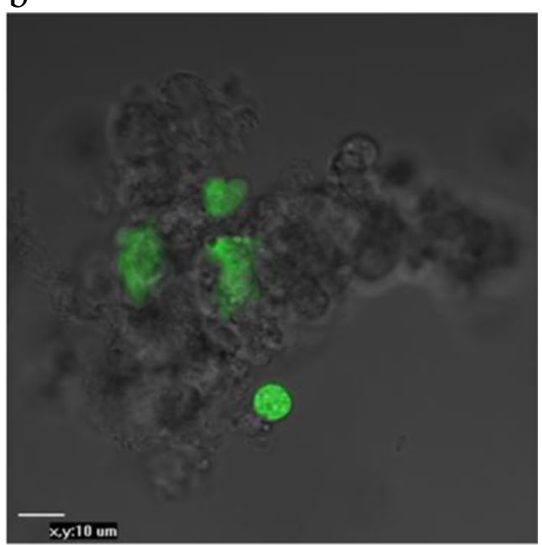

d

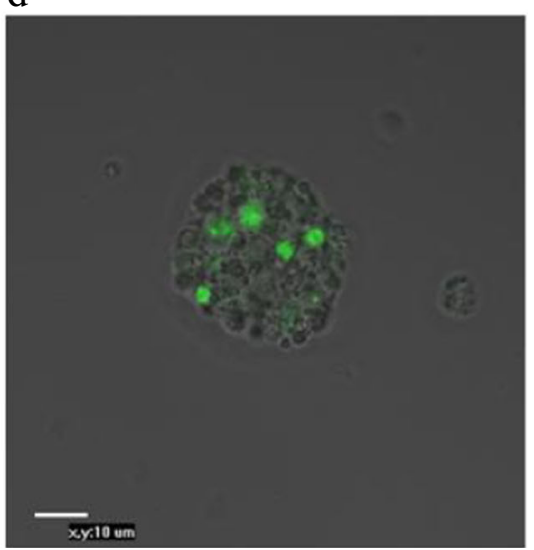


Fig. 6 The impacts of the purification and transfection methods on the percentage of transfected bPGCs. The different letters $(A-D)$ indicate statistically significant differences at a level of $\alpha=0.05$

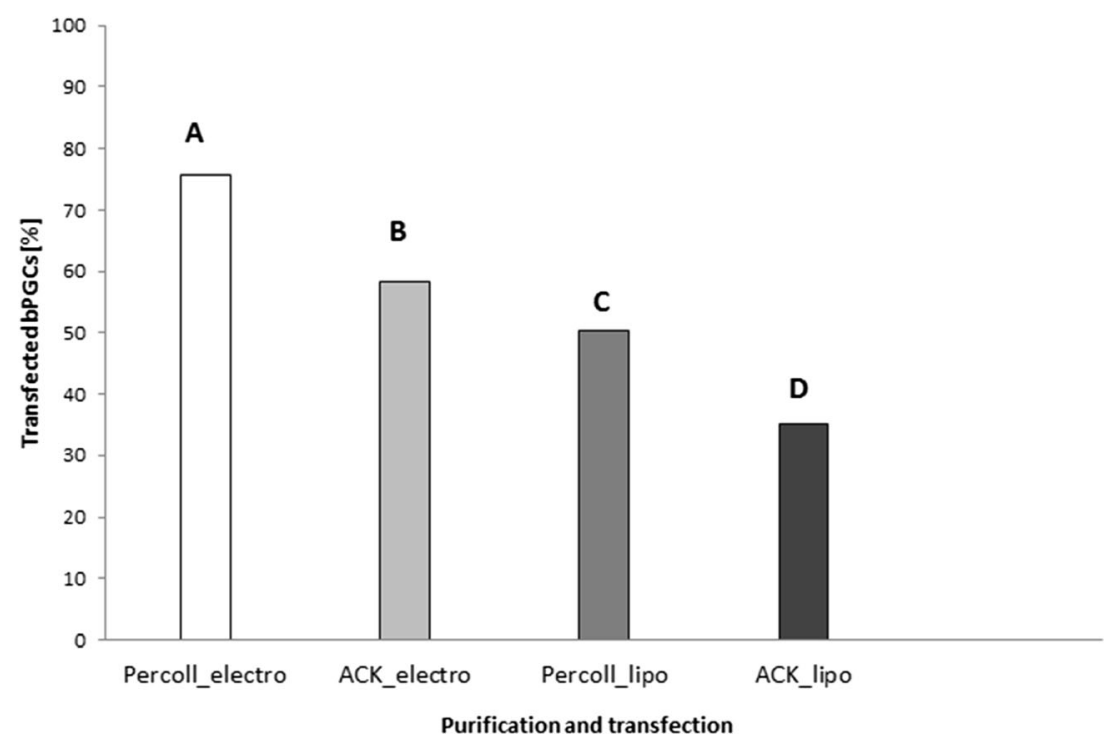

embryos. Figure 8 illustrates gonad cells dissected from 8day-old (34 HH) embryos emitting GFP fluorescence after excitation via an argon laser $(488 \mathrm{~nm})$. The PCR analysis detected the EGFP gene in the gonads of $44 \%$ of the embryos after injection of the modified bPGCs and $42 \%$ of the recipients after injection of the modified gPGCs (Figs. 9 and 10).

Analysis of germline chimeric chickens (G0)

Chimeric chickens were produced after injecting the modified PGCs with pC-OVAIFN/pC-OVAHBV. The hatch rate of the injected recipient embryos was $68.3 \%$. DNA isolated from the BCs and sperm were assessed by PCR to reveal that 4.9 and $16.7 \%$ of the transgenic hens and 3.5 and $2.4 \%$ of the transgenic roosters carried the hIFN $\alpha 2 \mathrm{a}$ gene and HBsAg antigen, respectively.

\section{Discussion}

The generation of transgenic chickens with PGCs, including the isolation and injection of these cells into the recipient embryos, production of germline chimeras and use of the chimeras to create transgenic birds through breeding programmes, is a complex process requiring an appropriate strategy. Some reports have compared the individual procedures that were included in our own research. For example, we can reference comparisons between the cells' origins (Kim et al. 2005), various methods of cells isolation (Mozdziak et al. 2005; Motono et al. 2010) and procedures for in vitro culture (Macdonald et al. 2010) or methods of transfection.

Our research focused on three main areas. First, it addressed PGCs isolation by indicating the effective purification methods and defining the effective transfection methods with a marker gene construct. Second, it assessed EGFP gene
Fig. 7 The impacts of the purification and transfection methods on the percentage of transfected gPGCs. The cases marked with the same letter did not statistically significantly differ at a level of $\alpha=0.05$

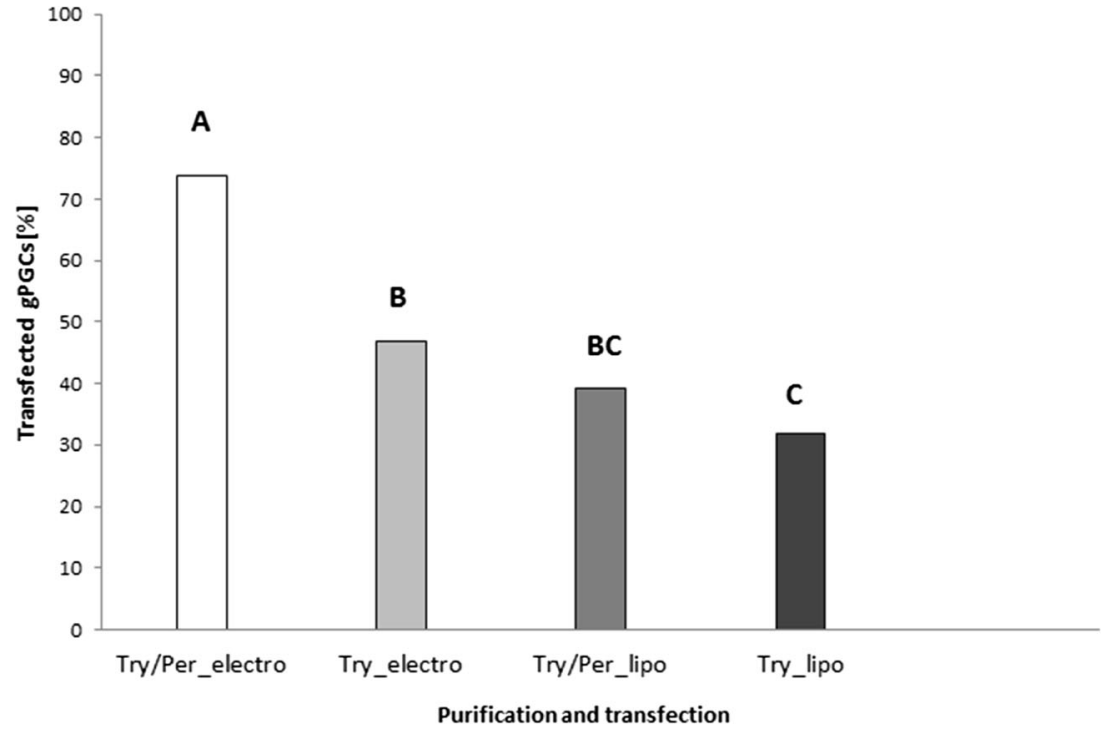


Table 2 Viability of recipient embryos after the injection of modified PGCs

\begin{tabular}{llll}
\hline Experimental group & $\begin{array}{l}\text { Total number } \\
\text { of embryos }\end{array}$ & $\begin{array}{l}\text { Percentage of } \\
\text { live embryos }\end{array}$ & $\begin{array}{l}\text { Percentage of } \\
\text { dead embryos }\end{array}$ \\
\hline $\begin{array}{l}\text { Injected embryos with } \\
\text { bPGCs }\end{array}$ & 26 & 88.5 & 11.5 \\
$\begin{array}{l}\text { Injected embryos with } \\
\text { gPGCs }\end{array}$ & 24 & 87.5 & 12.5 \\
$\begin{array}{l}\text { Embryos with window } \\
\text { for injection } \\
\text { Control }\end{array}$ & 10 & 80.0 & 20.0 \\
\hline
\end{tabular}

expression both in vitro and in vivo. Third, it addressed the construction of tissue-specific vectors under the control of the ovalbumin promoter and its surrounding enhancer sequences to transfection of the PGCs that were subsequently used to generate putative germline chimeras $(\mathrm{G} 0)$.

During the early stages of chicken development, PGCs move to the blood and migrate to the germinal ridges (future gonads), where they accumulate as gonadal germ cells (Motono et al. 2010; D'Costa et al. 2001). Previous

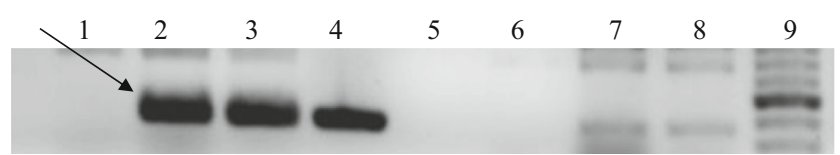

Fig. 9 Genomic PCR analysis of recipient embryos after bPGCs transfection (1\% agarose gel). $1-3,7,8$ genomic DNA isolated from gonads; 4 control DNA: pEGFP-N1; 5 control mix PCR; 6 total DNA from hen blood was used for the negative control; 9 ladder indicates size of fragments, narrow indicates fragment EGFP ( $407 \mathrm{bp})$

publications have provided information regarding the numbers of PGCs at subsequent developmental stages. Approximately 30 differentiating cells can be identified while PGCs are migrating through the embryonic cardiovascular system in the X stage of early development (Eyal-Giladi and Kochav 1976). During the subsequent germinal crescent stage, 200 250 cells can be observed (Tsunekawa et al. 2000) and during stage $31 \mathrm{HH}$ ( $31 \mathrm{HH}$ is at the beginning of the seventh day of incubation), more than 1000 cells are present (Zaccanti et al. 1990). These data illustrate the difficulties associated with determining the number of PGCs that would facilitate further manipulation. The application of modern isolation techniques (Mozdziak et al. 2005; Motono et al. 2010), such as MACS

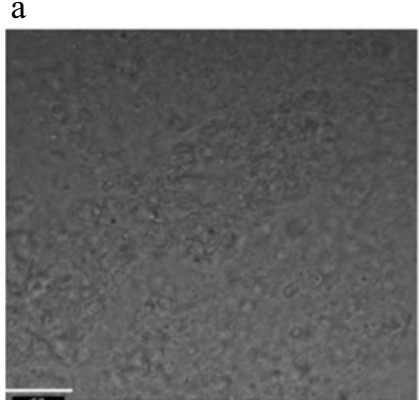

d

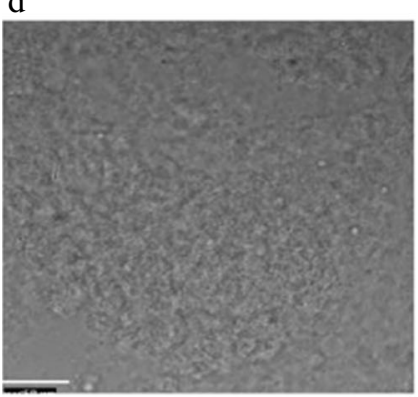

g

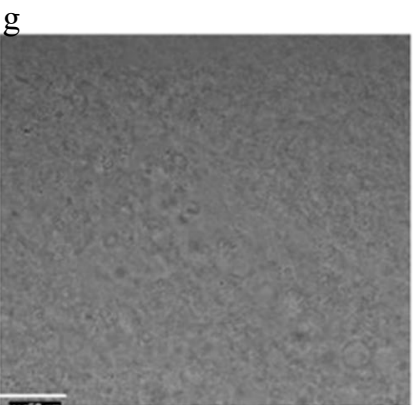

b

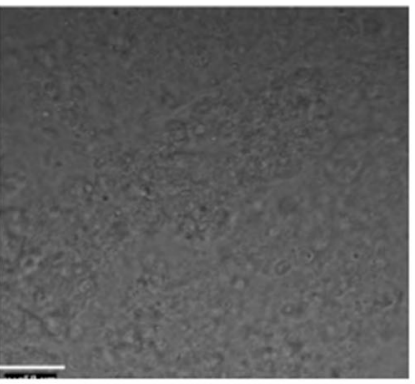

$\mathrm{e}$

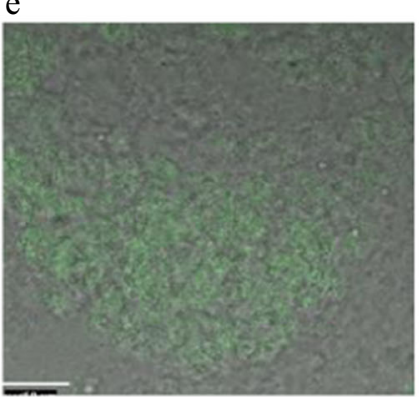

$\mathrm{h}$

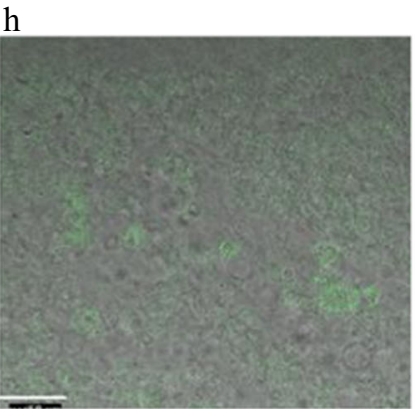

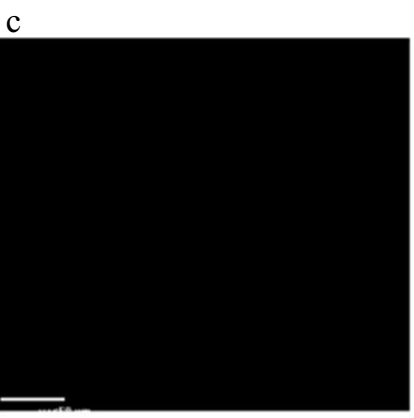

f

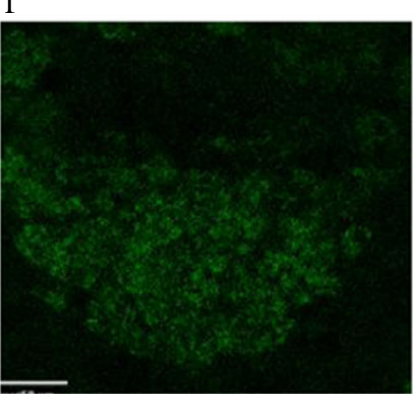

i

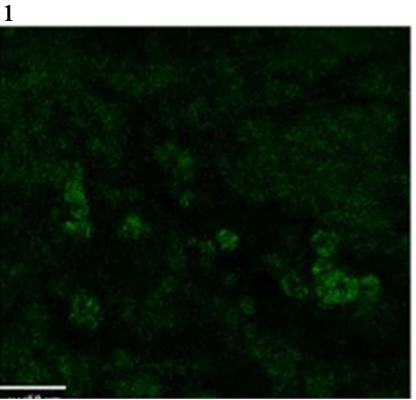




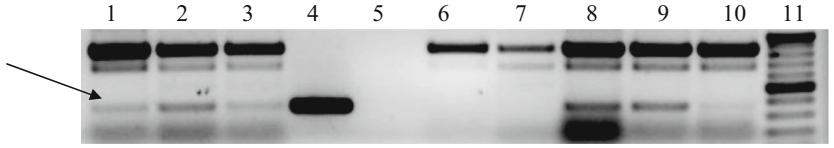

Fig. 10 Genomic PCR analysis of recipient embryos after gPGCs transfection (1\% agarose gel). $1-3,7-10$ total DNA isolated from gonads; 4 control DNA: pEGFP-N1; 5 control mix PCR; 6 total DNA from hen blood was used for the negative control; 11 ladder indicates size of fragments, narrow indicates fragment EGFP ( 407 bp)

and/or FACS, has yielded some progress in this area. Another method that led to an increase in the number of transfected cells was Percoll gradient centrifugation to fully remove the morphotic elements of blood, debris and dead and defective cells (Matás et al. 2011). Consequently, a uniform viable PGCs population was acquired for further manipulation. In our research, using PAS staining, FACS and an anti-SSEA-1 antibody, the presence of bPGCs was confirmed after purification by Percoll centrifugation. Oishi (2010) indicated that the purification of chicken PGCs on a Percoll gradient increased the effectiveness of both transient and stable transfection.

To demonstrate the migratory activities of the PGCs, we provide efficient and useful in vitro and in vivo techniques for PGCs, although the expression was transient. These cells were purified via Percoll centrifugation and then transfected with EGFP and injected into recipient embryos. The two methods of transfection, electroporation and lipofection, were compared to optimise PGCs transfection. After Percoll gradient centrifugation, the cells were observed to be very healthy (Fig. 2a, c), with no dead or damaged cells at any of the stages. The pEGFP-N1 vector was used for both the electroporation and lipofection experiments. The cells were cultured in a selective medium containing G418; this allowed us to nearly precisely define the percentages of the positively transfected cells resulting from the applied transfection methods. The cells that were not successfully transfected with the neomycin resistance cassette $\left(\mathrm{Neo}^{\mathrm{r}}\right)$-containing pEGFP-N1 plasmid did not produce the enzyme to digest G418 and consequently died. There are several factors which have a huge impact on the sensitivity of the cell population to antibiotics. These include not only the rate of the cell division but also the baseline level of toxicity. We applied the lowest but functional rate of G418 in the cultured media after transfection. The highest mean percentage of transfected bPGCs was $75.8 \%(95 \%$ CI: 73.5-78.1\%; Fig. 6), which was achieved using a combination of purification via Percoll centrifugation and transfection via electroporation. The positive results obtained with Percoll purification and electroporation were evident when compared with the results of ACK buffer purification and lipofection ( $\leq 9 \%)$. After using a commercial lipofectant, we observed slow cell division in the cultures, which indicated the possible presence of toxic substances. Additionally, the complete removal of the buffer during ACK lysis was difficult and, consequently, we observed that both the morphotic blood elements and the living PGCs were digested.

Furthermore, bPGCs that had purified via Percoll, transfected by electroporation and cultured in selective medium were injected into the recipient embryos; these embryos were left to develop further. We proved that PGCs following transfer to the recipient embryos did not lose their abilities to colonise the gonads. The PCR analysis of isolated embryonic gonadal DNA assesses the presence of the vector pEGFP-N1 sequence at the rate of $44 \%$. Using Percoll gradient centrifugation, we increased the number of living cells and, thereby, increased the uptake of foreign DNA.

As mentioned in previous publications, the injected and modified gPGCs can migrate to the recipients' gonads (Kagami et al. 1995; Hong et al. 1998), similarly to the bPGCs collected from blood. Therefore, we designed the in vivo gPGCs experiment with the intent to inject these cells into embryos, thus requiring the gPGCs to be purified by Percoll centrifugation and transfected with EGFP. In our research, the highest mean percentage of transfected cells was $73.8 \%$ (95 \% CI: 70.2-77.4 \%) after trypsin digestion, Percoll gradient purification and electroporation (Fig. 7). For the gPGCs, the results of this combined method were the most positive and yielded at least $9.5 \%$ more transfected cells when compared with cells that were treated with trypsin alone. The following factors had a significant impact on the transfection method efficiency and played key roles in ensuring the success of this process: properly adjusted electroporation parameters, the applied medium, the cell type and the selected equipment (van de Lavoir et al. 2006). In principle, for nonadherent cells, electroporation is the proper nucleic acid transfection method rather than the commercially available synthetic lipid-based transfection reagents. We confirmed the abilities of transfected PGCs to migrate to and colonise gonads based on the observation of EGFP ${ }^{+}$PGCs in mashed gonads (Fig. 8) and PCR. The PCR analysis of the recipient embryonic gonads, which allowed the identification of EGFP gene transfection, demonstrated the comparable effectiveness of the transfections of both bPGCs and gPGCs, in response to which modifications were observed in 44 and $42 \%$ of the gonads, respectively (Figs. 9 and 10). Thus, the presence of exogenous DNA in the gonads of embryos does not necessarily indicate the stable germline in chickens (Naito et al. 2007).

Few reports have described the successful use of non-viral methods and solutions are required for various associated problems. To maximise germline transmission, we modified our cell-isolation method to increase the purity of PGCs. Percoll density gradient centrifugation of purified chicken cells was used by Oishi (2010) and this method was also found to increase the efficiencies of both transient and stable DNA transfection of chicken PGCs. We understand how combinations of proliferation factors can limit or increase the PGCs growth in culture. Macdonald et al. (2010) and Choi et al. 
(2010) have shown conclusively that bFGF is essential for the survival of chicken PGCs in culture. We cultured transfected PGCs in medium C: supplemented bFGF, mLIF and hSCF. After 14 days of PGCs culture, few fluorescing cells were observed (Fig. 5). This suggested that stable integration of the EGFP into the PGCs chromosome is required for its expression.

We recently demonstrated (Chojnacka-Puchta et al. 2012) that the introduction of an ovalbumin-modified, GFPexpressing base vector into cultured chicken oviduct epithelial cells yielded strong fluorescence. This finding allowed us to create identical, final, tissue-specific constructs of pC_OVAHBV and pC_OVAIFN. These constructed vectors could potentially be used to generate transgenic chickens. The simplest solutions could exert large impacts on commercialscale protein production. The accuracy of our promoter-enhancer combination allowed us to design expression vectors that, when used to modify PGCs, could also be used to generate transgenic chickens. In accordance with this idea, we created constructs that included the genes encoding IFN $\alpha 2 \mathrm{a}$ and the hepatitis-associated cell surface proteins preS1 and preS2/S under the control of the ovalbumin promoter and strengthening sequences, which included the chicken oviduct-specific and enhancer-like (COSE) region and ERE. An analysis of the current publications allows us to state that, to use the potential generated by PGCs, a construct with the maximum expression potential should be designed. The present results support the idea that transcriptionally quiescent germ cells, which are prone to switching off transgene expression (Seydoux and Braun 2006), require suppressors or enhancers to maximise cytoplasmic export and stabilisation of the mRNA transcript (Seo et al. 2010). The latest research has proven that the perfect tool for reducing epigenetic silencing is the 'cut and paste' transposon (Macdonald et al. 2012; Park and Han 2012). However, the use of the transposon miniTol2 in the directed transfection of in vivo PGCs has been suggested by Tyack et al. (2013) to fully eliminate the difficulties related to the PGCs culture and retrovirus use. It will be necessary to analyse this method further and to determine, for example, the impact of strengthening sequences such as the central polypurine track element on the expression of the analysed protein in epithelial cells from the chicken oviduct (Jung et al. 2011).

This PGCs technology (Fig. 11) has been successfully applied in the project titled "The germ cells modification and obtaining of birds carrying the genes of therapeutic proteins" (National Center for Research and Development, grant no. $\mathrm{N}$ $\mathrm{R} 120110$ 10). The basic strategy of this grant is to obtain the generation of transgenic birds that synthesise recombinant therapeutic protein to a secretory tissue in the oviduct of laying hens. In this project, we used a non-viral ovalbumin promoter system to modify the PGCs to express the human IFN $\alpha$ gene and HBsAg. The generated G0 birds were screened in a PCR assay and the following expression percentages were obtained for the transgenes hIFN $\alpha 2 \mathrm{a}$ and HBsAg, respectively: hens DNA (4.9 and $16.7 \%$ ) and roosters DNA (3.5 and $2.4 \%$ ). Test mating G0 (data not shown) carrying the $\mathrm{hIFN} \alpha 2 \mathrm{a}$ gene allowed to obtained germline transmission G1 at levels of 6.7, 5 and $2.3 \%$, depending on three individuals of roosters. In case of the HBsAg antigen, the germline transmission rate after mating one rooster with seven hens was at the level of $34.2 \%$. In doing so, we proved that donorderived functional gametes could be produced from the putative chimeric chickens. In future studies, we will collect eggs laid by the transgenic $\mathrm{G} 1$ and $\mathrm{G} 2$ hens and test for the presence

$$
\text { PC_OVAIFN }
$$

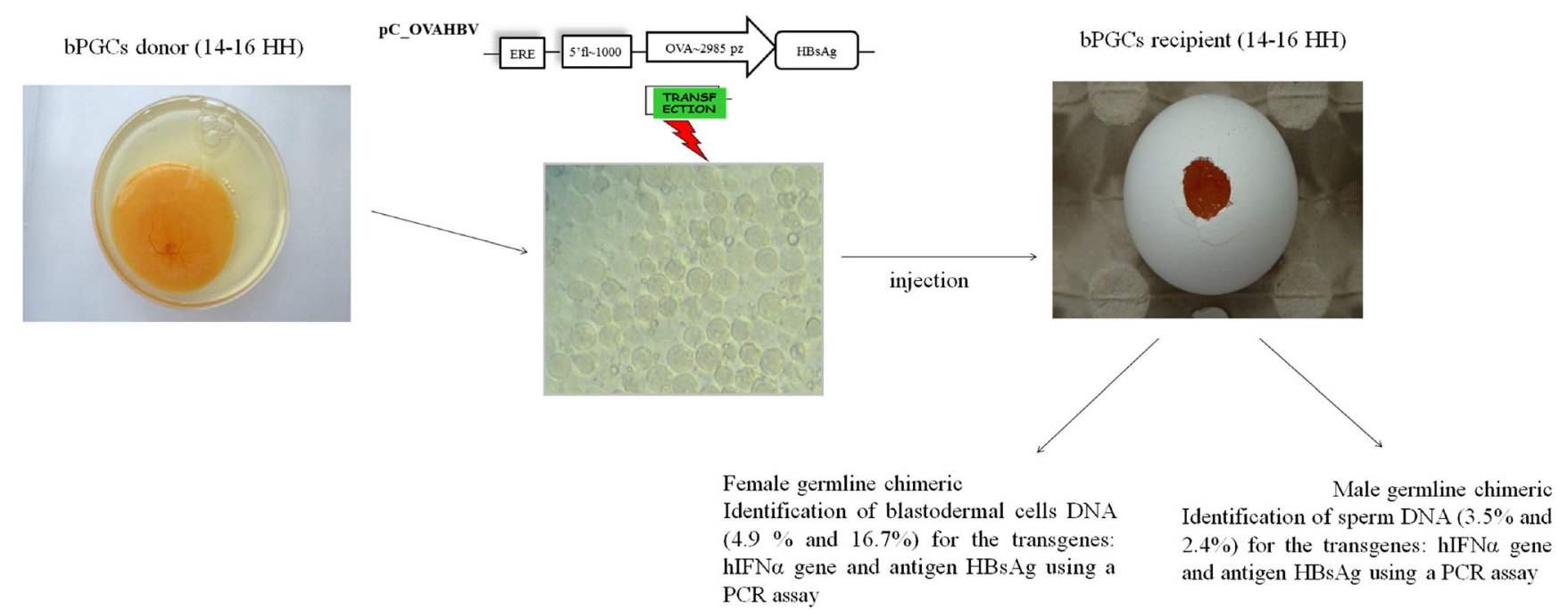

Fig. 11 Outline of the final in vitro and in vivo studies; effectiveness of the applied methods 
of recombinant proteins in the egg whites using an enzymelinked immunosorbent assay (ELISA).

Acknowledgments We thank Agata Jagiełło, Violetta CecudaAdamczewska, Marcin Zieliński, Małgorzata Lichocka and Marta Brewińska-Olchowik for their assistance, time and effort.

Author contributions Conceived and designed the experiments: LChP, DS, GP, MB, AP. Performed the experiments: LChP, DS, PL. Analysed the data: LChP, DS. Wrote the paper: LChP. Corrected and edited the manuscript: LChP, DS, MB.

Ethical standards All procedures and protocols used in this study were approved by Second Warsaw Local Ethics Committee for Animal Experimentation.

Grant support The work reported herein was supported by the National Center for Research and Development, grant no. N R12 011010.

Open Access This article is distributed under the terms of the Creative Commons Attribution License which permits any use, distribution, and reproduction in any medium, provided the original author(s) and the source are credited.

\section{References}

Bednarczyk M, Płucienniczak G, Płucienniczak A, Łakota P, Sochanik A, Dłużniewska P, Grajewski B (2003) Expression of exogenous genes in blastodermal cells of chicken in vitro. Folia Biol (Krakow) 51(34):189-194

Brinster RL, Chen HY, Trumbauer M, Senear AW, Warren R, Palmiter RD (1981) Somatic expression of herpes thymidine kinase in mice following injection of a fusion gene into eggs. Cell 27:223-231

Choi JW, Kim S, Kim TM, Kim YM, Seo HW, Park TS, Jeong JW, Song G, Han JY (2010) Basic fibroblast growth factor activates MEK/ ERK cell signaling pathway and stimulates the proliferation of chicken primordial germ cells. PLoS One 5(9):e12968. doi:10. 1371/journal.pone.0012968

Chojnacka-Puchta L, Kasperczyk K, Płucienniczak G, Sawicka D, Bednarczyk M (2012) Primordial germ cells (PGCs) as a tool for creating transgenic chickens. Pol J Vet Sci 15(1):181-188

D'Costa S, Pardue SL, Petitte JN (2001) Comparative development of avian primordial germ cells and production of germ line chimeras. Avian Poult Biol Rev 12(4):151-168. doi:10.3184/147020601783698477

Eyal-Giladi H, Kochav S (1976) From cleavage to primitive streak formation: a complementary normal table and a new look at the first stages of the development of the chick. I. General morphology. Dev Biol 49:321-337

Freshney RI (1987) Culture of animal cells, 2nd edn. Wiley-Liss, New York

Gordon JW, Ruddle FH (1981) Integration and stable germ line transmission of genes injected into mouse pronuclei. Science 214:1244-1246

Hamburger V, Hamilton HL (1951) A series of normal stages in the development of the chick embryo. J Morphol 88:49-92

Hong YH, Moon YK, Jeong DK, Han JY (1998) Improved transfection efficiency of chicken gonadal primordial germ cells for the production of transgenic poultry. Transgenic Res 7(4):247-252

Jung JG, Park TS, Kim JN, Han BK, Lee SD, Song G, Han JY (2011) Characterization and application of oviductal epithelial cells in vitro in Gallus domesticus. Biol Reprod 85(4):798-807

Kagami H, Clark ME, Verrinder Gibbins AM, Etches RJ (1995) Sexual differentiation of chimeric chickens containing $\mathrm{ZZ}$ and $\mathrm{ZW}$ cells in the germline. Mol Reprod Dev 42:379-387
Kim JN, Lee YM, Park TS, Jung JG, Cho BW, Lim JM, Han JY (2005) Detection and characterization of primordial germ cells in pheasant (Phasianus colchicus) embryos. Theriogenology 63:1038-1049

Macdonald J, Glover JD, Taylor L, Sang HM, McGrew MJ (2010) Characterisation and germline transmission of cultured avian primordial germ cells. PLoS One 5(11):e15518

Macdonald J, Taylor L, Sherman A, Kawakami K, Takahashi Y, Sang HM, McGrew MJ (2012) Efficient genetic modification and germline transmission of primordial germ cells using piggyBac and Tol2 transposons. Proc Natl Acad Sci U S A 109(23):E1466-E1472

Matás C, Vieira L, García-Vázquez FA, Avilés-López K, López-Úbeda R, Carvajal JA, Gadea J (2011) Effects of centrifugation through three different discontinuous Percoll gradients on boar sperm function. Anim Reprod Sci 127(1-2):62-72

McGrew MJ, Sherman A, Ellard FM, Lillico SG, Gilhooley HJ, Kingsman AJ, Mitrophanous KA, Sang H (2004) Efficient production of germline transgenic chickens using lentiviral vectors. EMBO Rep 5:728-733

Motono M, Yamada Y, Hattori Y, Nakagawa R, Nishijima K, Iijima S (2010) Production of transgenic chickens from purified primordial germ cells infected with a lentiviral vector. J Biosci Bioeng 109: 315-321

Mozdziak PE, Petitte JN (2004) Status of transgenic chicken models for developmental biology. Dev Dyn 229:414-421

Mozdziak PE, Angerman-Stewart J, Rushton B, Pardue SL, Petitte JN (2005) Isolation of chicken primordial germ cells using fluorescence-activated cell sorting. Poult Sci 84:594-600

Naito M, Minematsu T, Harumi T, Kuwana T (2007) Intense expression of GFP gene in gonads of chicken embryos by transfecting circulating primordial germ cells in vitro and in vivo. J Poult Sci 44:416-425

Oishi I (2010) Improvement of transfection efficiency in cultured chicken primordial germ cells by percoll density gradient centrifugation. Biosci Biotechnol Biochem 74(12):2426-2430

Park TS, Han JY (2012) piggyBac transposition into primordial germ cells is an efficient tool for transgenesis in chickens. Proc Natl Acad Sci U S A 109(24):9337-9341

SAS Institute Inc. (2010) SAS/STAT ${ }^{\circledR} 9.22$ User's Guide. SAS Institute Inc., Cary

Seo HW, Kim TM, Choi JW, Han BK, Song G, Han JY (2010) Evaluation of combinatorial cis-regulatory elements for stable gene expression in chicken cells. BMC Biotechnol 10:69. doi:10.1186/ 1472-6750-10-69

Seydoux G, Braun RE (2006) Pathway to totipotency: lessons from germ cells. Cell 127(5):891-904

Sokal RR, Rohlf FJ (1995) Biometry: principles and practice of statistics in biological research. W. H. Freeman, San Francisco

Song G, Park TS, Kim TM, Han JY (2010) Avian biotechnology: Insights from germ cell-mediated transgenic system. J Poult Sci 47(3):197207. doi:10.2141/jpsa.009108

Tsunekawa N, Naito M, Sakai Y, Nishida T, Noce T (2000) Isolation of chicken vasa homolog gene and tracing the origin of primordial germ cells. Development 127:2741-2750

Tyack SG, Jenkins KA, O'Neil TE, Wise TG, Morris KR, Bruce MP, McLeod S, Wade AJ, McKay J, Moore RJ, Schat KA, Lowenthal JW, Doran TJ (2013) A new method for producing transgenic birds via direct in vivo transfection of primordial germ cells. Transgenic Res 22(6):1257-1264

van de Lavoir MC, Diamond JH, Leighton PA, Mather-Love C, Heyer BS, Bradshaw R, Kerchner A, Hooi LT, Gessaro TM, Swanberg SE, Delany ME, Etches RJ (2006) Germline transmission of genetically modified primordial germ cells. Nature 441(7094):766-769

Yamamoto Y, Usui F, Nakamura Y, Ito Y, Tagami T, Nirasawa K, Matsubara Y, Ono T, Kagami H (2007) A novel method to isolate primordial germ cells and its use for the generation of germline chimeras in chicken. Biol Reprod 77(1):115-119

Zaccanti F, Vallisneri M, Quaglia A (1990) Early aspects of sex differentiation in the gonads of chick embryos. Differentiation 43:71-80 